\title{
Geo-referencing livestock farms as tool for studying cystic echinococcosis epidemiology in cattle and water buffaloes from southern Italy
}

Giuseppe Cringoli ${ }^{1}$, Laura Rinaldi ${ }^{1}$, Vincenzo Musella ${ }^{1}$, Vincenzo Veneziano ${ }^{1}$, Maria Paola Maurelli', Francesco Di Pietro², Michele Frisiello², Salvatore Di Pietro ${ }^{2}$

${ }^{1}$ Department of Pathology and Animal Health, University of Naples "Federico II", Naples, Italy;

${ }^{2}$ Veterinary Service ASL AV 1, Avellino, Italy

Abstract. Cystic echinococcosis (CE), caused by the larval stages of the tapeworm Echinococcus granulosus, is known to be one of the most important parasitic infection in livestock worldwide and one of the most widespread zoonoses known. In the present study, we used a geographical information system (GIS) to study the spatial structure of livestock (cattle, water buffaloes and sheep) populations to gain a better understanding of the role of sheep as reservoir for the transmission of CE to cattle and water buffaloes. To this end, a survey on CE in cattle and water buffaloes from the Campania region of southern Italy was conducted and the geo-referenced results linked to the regional farm geo-referenced data within a GIS. The results showed a noteworthy prevalence of CE in cattle and water buffalo farms (overall prevalence $=18.6 \%$ ). The elaboration of the data with a GIS approach showed a close proximity of the bovine and/or water buffalo CE positive farms with the ovine farms present in the study area, thus giving important information on the significance of sheep and free-ranging canids in the transmission cycles of CE in relation to cattle and water buffaloes. The significantly higher prevalence found in cattle as compared to water buffalo farms $(20.0 \%$ versus $12.4 \%)$ supports the key role of sheep in the CE transmission; indeed, within the $5 \mathrm{~km}$ radius buffer zones constructed around the cattle farms positive for CE, a higher number of (potentially infected) sheep farms were found compared to those found within the buffer zones around the water buffalo farms. Furthermore, the average distances between the sheep and cattle farms falling in the same buffer zones were significantly lower than those between the sheep and water buffalo farms. We emphasize that the use of GIS is a novel approach to further our understanding of the epidemiology and control of $\mathrm{CE}$ and we encourage other groups to make use of it.

Keywords: cystic echinococcosis; cattle; water buffaloes; sheep; geographical information systems.

\section{Introduction}

Echinococcosis is a cosmopolitan parasitic disease caused by adult or larval stages of tapeworms belonging to the genus Echinococcus Rudolphi, 1801. Within the genus Echinococcus four species

\footnotetext{
Corresponding author:

Giuseppe Cringoli

Dipartimento di Patologia e Sanità Animale

Facoltà di Medicina Veterinaria

Università degli Studi di Napoli "Federico II"

Via della Veterinaria, 1 - 80137 Napoli, Italy

Tel. +39 081 2536283; Fax +39081 2536282

E-mail: cringoli@unina.it

website: www.parassitologia.unina.it
}

are presently recognised, namely E. granulosus, E. multilocularis, E. oligarthrus and E. vogeli. In addition, a new sibling species, E. shiquicus, has recently been reported from Tibet (Xiao et al., 2005; Nakao et al., 2007).

Cystic echinococcosis (CE) is caused by the larval stages (hydatid cysts) of E. granulosus and is known as one of the most important parasitic infection in livestock in the world (Capuano et al., 2006). It can establish itself in many different hosts, including humans, and is regarded as one of the most widespread zoonoses (Craig et al., 2007). Molecular techniques have allowed the identification of 10 different genotypes (G1-G10) of the par- 
asite (Nakao et al., 2007).

The present paper is focused on E. granulosus whose distribution, apart from being correlated to particular types of livestock production, is seemingly also determined by climatic requirements, particularly temperature and rainfall (Romig, 2003).

The life cycle of E. granulosus includes dogs and other canids as the definitive hosts of the adult parasite, whilst sheep and numerous ungulates (e.g. cattle, water buffaloes, goats and pigs) are intermediate hosts, harbouring the hydatid cysts (Moro and Schantz, 2006; Craig et al., 2007). Dogs usually acquire the infection from hydatid-carrying livestock (especially sheep) as a result of their deliberate feeding of infested offal (liver and lungs) by owners who practise home-slaughter (McManus et al., 2003). The prevalence of CE in sheep is usually higher than in other animals (Daryani et al., 2007). For example, in the Sardinia island of Italy, $75 \%$ of sheep have recently been reported positive for CE (Scala et al., 2006), and in sheep from the Campania region of southern Italy $\mathrm{CE}$ is widespread with prevalences above $30 \%$ in some areas (Cringoli et al., unpublished data). Other recent studies have demonstrated CE prevalence values of $14.8 \%$ in cattle (Veneziano et al., 2004) and $10.5 \%$ in water buffaloes (Capuano et al., 2006) bred in the Campania region.

These prevalence values are noteworthy, considering that illegal farm-slaughter is generally absent and that cattle and water buffaloes are slaughtered only in a few large, modern and efficient abattoirs, where the presence of canids is strictly forbidden. For these reasons, it is highly unlikely that dogs or other canids in this region may have the opportunity to feed on cattle and/or water buffalo carcasses. In the present study, this conundrum has been approached with a geographical information system (GIS) as a powerful descriptive and analytical tool for understanding the role of sheep as reservoir, together with free-ranging canids, for the transmission of CE to cattle and water buffaloes. For this purpose, a survey on CE in cattle and water buffaloes from the Campania region was conducted based on the spatial structure of livestock populations; the geo-referenced results were linked to the regional farm geo-referenced data and analyzed within a GIS.

\section{Materials and methods}

\section{Geo-referencing of livestock farms}

Within the activities of a regional project (Active Monitoring of Zootecnical Population - MAPZOO), a GIS (ArcGIS version 9.2, ESRI, Redlands, CA, USA) of the Campania region, southern Italy, was constructed utilizing as data-layers:

(i) the topographic base map of the Italian Geographic Military Institute (IGM) at a scale of $1: 25,000$; and

(ii) the digital aerial photos of the Cartographic Office of the Campania region, at an $1.0 \mathrm{~m} \mathrm{spa-}$ tial resolution.

Based on this GIS, all the cattle, water buffalo and sheep farms present on the whole territory of the Campania region (each coded by a specific ID) were geo-referenced on digital aerial photos, a technique which is less expensive and more precise than the traditional use of global positioning system (Cringoli et al., 2005; Rinaldi et al., 2006). This geo-referencing (Fig. 1) was done based on the knowledge of the location of farms by veterinarians working at the local veterinary services (ASL).

\section{Examination of slaughtered animals}

From January to September 2006, animals from 3199 farms (2587 breeding only cattle and 612 breeding only water buffaloes) were examined for $\mathrm{CE}$ at one of the biggest slaughterhouses in southern Italy, the "Realbeef" of the Cremonini Group, located in the Avellino province. Each animal was accurately inspected in order to detect hydatid cysts. Specifically, liver and lungs of the slaughtered livestock were examined for hydatid cysts by visual inspection, palpation, and serial cuts of the organ(s). The origin of each animal, i.e. the ID of the farm 


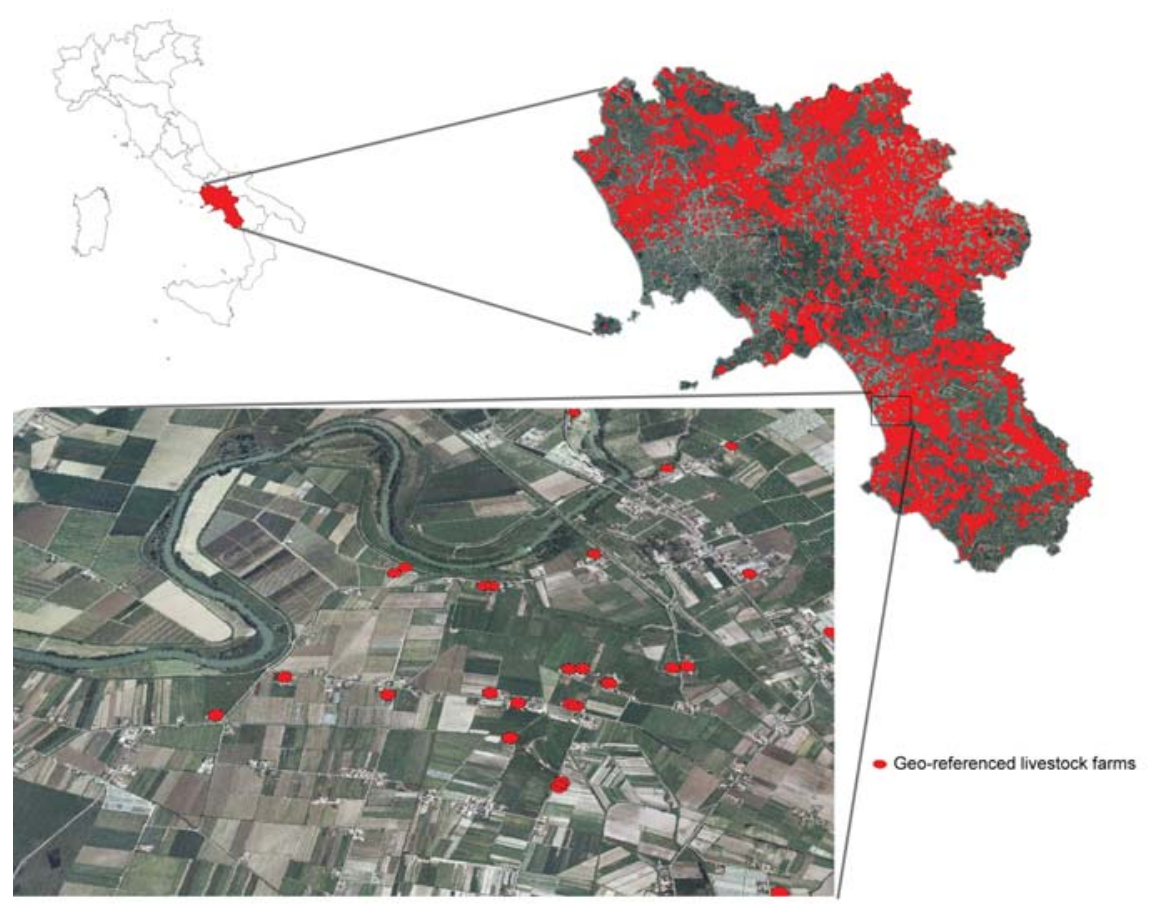

Fig. 1. The Campania region of southern Italy with geo-referenced livestock (cattle, water buffalo and sheep) farms.

they came from, was also registered.

All farm IDs were compared with those present in the MAPZOO GIS database and the category of each farm (cattle or water buffalo breeding) could thus be extracted.

\section{Data-mapping}

In order to display the spatial distribution of $\mathrm{CE}$ in cattle and water buffalo farms (used as epidemiological units in our study), as well as the spatial distribution of sheep farms present in the study area, a point map was drawn up within the GIS.

\section{GIS analysis}

The buffer generation and neighbourhood analysis functions of GIS were used. Specifically, circular buffer zones of $5 \mathrm{~km}$ radius (considered as home range for free-ranging canids) were constructed around each cattle and buffalo farm found positive for CE. Then, within each buffer zone:

(i) all the sheep farms present were counted; and

(ii) the distances between each cattle and buffalo farm and each sheep farm calculated and averaged.

\section{Statistical analysis}

Pearson's chi-square test for independence was used in order to test differences in the CE prevalence among the cattle and water buffalo farms.

The mean, standard deviation (SD), and 25th, 50th and 75th percentiles of distances from the sheep farms within each buffer zone were calculated for the cattle and water buffalo farms that had tested positive to CE. The non-parametric Mann-Whitney U test was used in order to test differences among the above averaged values (distances from sheep farms in the buffer zone) in cattle and water buffalo farms.

All statistical analyses were performed using SPSS 13.0 software for Windows. 


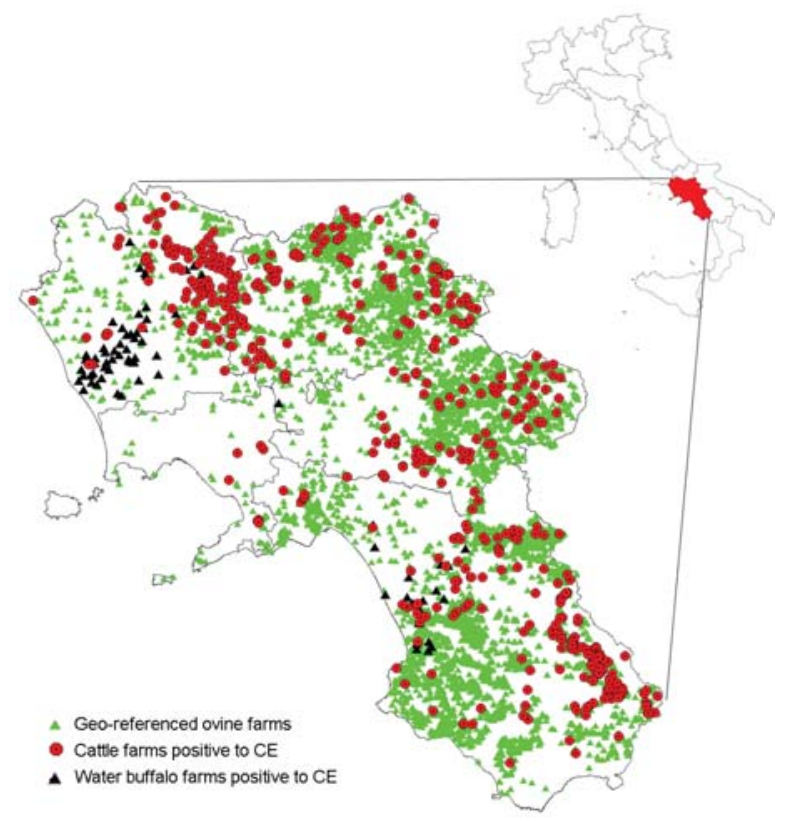

Fig. 2. Point map showing the distribution of cattle and water buffalo farms positive for CE and the distribution of the georeferenced ovine farms in the study area.

\section{Results}

Out of the 3199 farms examined, 594 (prevalence = $18.6 \% ; 95 \%$ confidence interval $(\mathrm{CI})=17.2-20.0 \%$ ) presented at least one animal infected by CE. When the farms were differentiated with regard to type of breeding, the CE prevalence values were as follows: $20.0 \%(518 / 2587 ; 95 \% \mathrm{CI}=18.5-21.6 \%)$ in cattle farms; and $12.4 \%(76 / 612$; $95 \% \mathrm{CI}=10.0-15.4 \%)$ in water buffalo farms. This higher prevalence for CE in cattle than in water buffalo farms was statistically significant $($ Pearson chi-square $=166.8 ; \mathrm{P}<0.001)$.

The point map in Figure 2 shows the location of the cattle and water buffalo farms positive to CE, as well as the location of the sheep farms present in the study area.

Table 1 summarises the data regarding the number of sheep farms present within the $5 \mathrm{~km}$ radius buffer zones constructed around the cattle and water buffalo farms that had tested positive for CE, as well as the data regarding their distances.

Overall, the mean number of sheep farms, present in the $5 \mathrm{~km}$ radius buffer zones around the cattle farms positive for CE, was higher than that around the water buffalo farms. In addition, within the buffer zones, the distances from sheep farms were significantly lower $(\mathrm{P}<0.001)$ for cattle than for water buffaloes (Fig. 3).

Table 1. Data on sheep farms (number and distances) present within the $5 \mathrm{~km}$ radius buffer zones constructed around the cattle and water buffalo farms positive for CE, as well as the data regarding their distances.

\begin{tabular}{|c|c|c|c|c|c|c|c|}
\hline \multirow{2}{*}{$\begin{array}{l}\text { Farm } \\
\text { typology }\end{array}$} & \multirow{2}{*}{$\begin{array}{l}\text { Mean no. of sheep } \\
\text { farms within the buffer } \\
\text { zones }\end{array}$} & \multicolumn{6}{|c|}{ Distances from sheep farms within each buffer zone } \\
\hline & & Mean & SD & $\begin{array}{l}\text { 25th } \\
\text { percentile }\end{array}$ & $\begin{array}{l}\text { 50th } \\
\text { percentile }\end{array}$ & $\begin{array}{l}\text { 75th } \\
\text { percentile }\end{array}$ & $\mathrm{P}^{*}$ \\
\hline Cattle & 10.7 & 2.2 & 1.8 & 1.0 & 1.9 & 2.7 & 0.000 \\
\hline Buffalo & 6.4 & 4.7 & 2.3 & 2.6 & 5.1 & 6.5 & \\
\hline
\end{tabular}

*Mann Whitney U test 


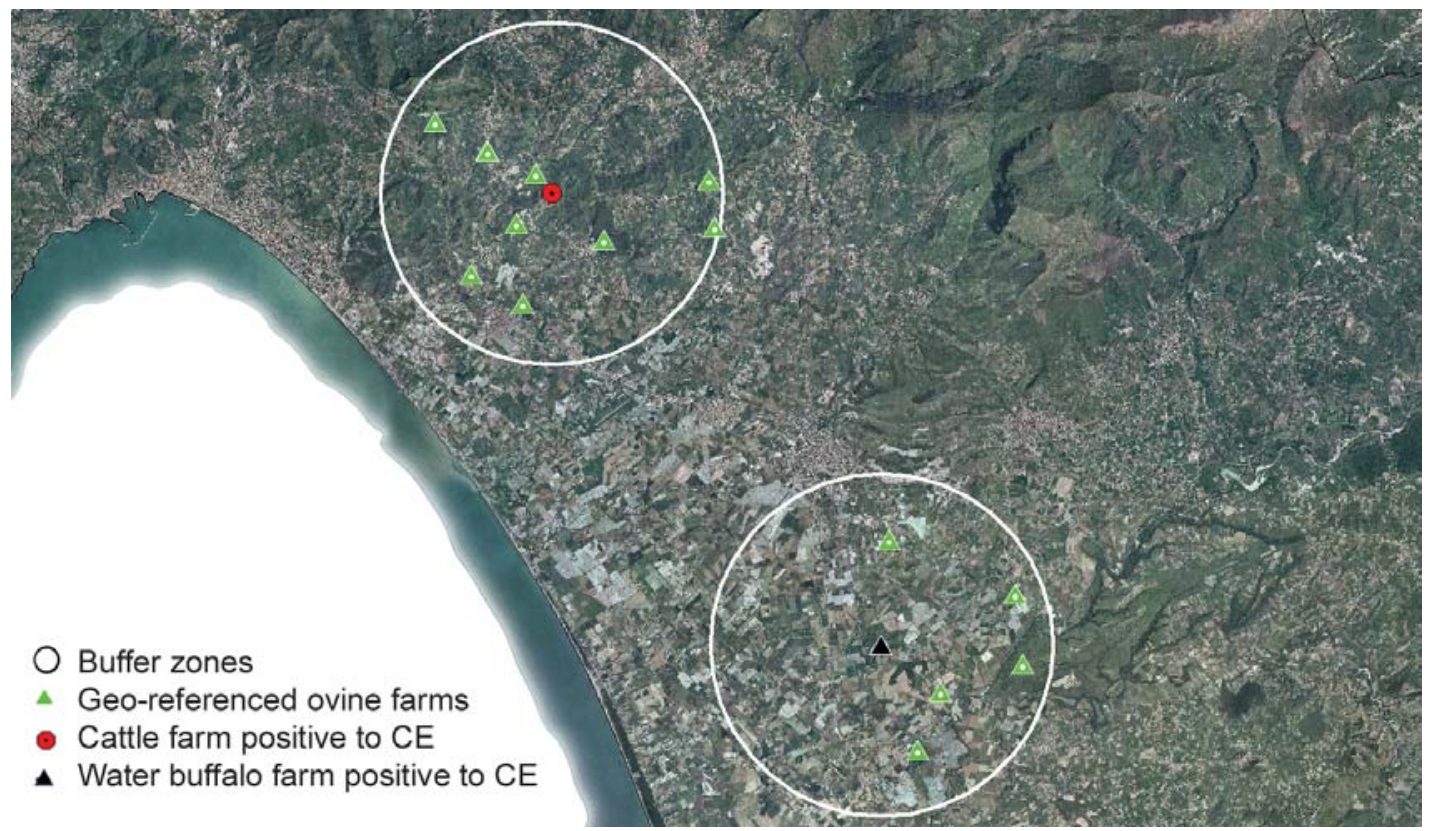

Fig. 3. Example of $5 \mathrm{~km}$ radius buffer zones constructed around cattle and water buffalo farms resulted positive for CE, and sheep farms falling into.

\section{Discussion}

Epidemiological studies from all parts of the world have shown that sheep is the key reservoir for E. granulosus (e.g. Romig, 2003; Scala et al., 2004; Battelli et al., 2007; Daryani et al., 2007). In the present paper we showed the utility of GIS as a tool for the study of the geographical inter-relationships between cattle, water buffalo and sheep farms with regard to the risk and potential of transmission of CE. This approach could be useful and practical, in order to study CE epidemiological patterns also in other zones where this infection is endemic. GIS has been previously used to study clustering of E. granulosus infection in macropodids in Australia (Barnes et al., 2007), and spatial modelling and ecology of E. multilocularis transmission in Germany (Staubach et al., 2001; Conraths et al., 2003) and China (Danson et al., 2003, 2006; Graham et al., 2004).

In Italy, cattle and water buffaloes are used as dairy animals; they represent an important economic resource for the industry of milk and milk-derived products. Due to their high economic value and strong inforcement of the Italian veterinary surveillance law, these farms are very well organized and, as a consequence, illegal slaughter is absent. In fact, cattle and water buffaloes are slaughtered only in a few large, modern and efficient abattoirs, where the offal is destroyed and where the presence of canids is strictly forbidden. For these reasons, it is highly unlikely that dogs and/or other canids may feed on cattle and/or water buffalo remains.

Thus, geo-referencing of livestock farms within an established GIS was useful for confirming the role of the sheep in the CE transmission to cattle and water buffaloes. In fact, the close proximity of the bovine and/or water buffalo positive farms with the ovine farms present in the study area was clearly shown. The key role of sheep was assessed for the CE transmission in cattle and water buffaloes. It should be noted that sheep are the intermediate host of choice for E. granulosus (Scala et al., 2004) and it is also important to consider the low commercial value of sheep carcasses in contrast to those of cattle and water buffaloes. As a result, sheep are often slaughtered at home and the carcasses of sheep which die 
on the pastures are generally left where they have fallen (Scala et al., 2004).

The significantly higher prevalence for CE found in cattle farms in comparison to water buffalo farms $(20.0 \%$ versus $12.4 \%)$, discovered in the present study, can be explained by the relative vicinity of sheep, a fact which thus plays a key role in the CE transmission in the area studied. Indeed, within the $5 \mathrm{~km}$ buffer zones constructed around the cattle farms positive for CE, a higher number of (potentially infected) sheep farms were found compared to those found within the buffer zones around the water buffalo farms. Furthermore, the average distance between the sheep and cattle farms that were found in the same buffer zones were significantly lower than that between the sheep and water buffalo farms.

It is likely that free-ranging canids became infected by CE when feeding on sheep carcasses in the sheep farms, and then went on to shed infectious eggs in proximate cattle/buffalo farms. Not surprisingly, the closer the sheep farms were to the cattle/water buffalo farms, the higher the risk of infection of the latter animals. The findings of the present study are further supported by the fact that cattle, water buffaloes and sheep bred in the Campania region of southern Italy share the same genotypes of E. granulosus, i.e. G1 (common sheep strain), G2 (Tasmanian sheep strain) and G3 (buffalo strain) (Capuano et al., 2006; Rinaldi et al., 2007), which constitute the sub-species E. granulosus sensu stricto (Nakao et al., 2007).

In conclusion, the results of the present study confirm that the spatial structure of animal populations and the characteristics of disease transmission (within farms and between farms through animal movement) can be dealt with using powerful descriptive and analytical tools such as those provided by GIS (Cringoli et al., 2005; Rinaldi et al., 2006).

\section{References}

Barnes TS, Morton JM, Coleman GT, 2007. Clustering of hydatid infection in macropodids. Int J Parasitol 37, 943-952. Battelli G, Guazzetti S, Micagni G, Ostanello F, 2007.
Bovine echinococcosis in non-endemic area of northern Italy: an example of integrated analysis of passive surveillance data. Proceedings of the $22^{\text {th }}$ International Coongressof Hydatidology, Athens, Greece, 15-19 ${ }^{\text {th }}$ May 2007, 131-133.

Capuano F, Rinaldi L, Maurelli MP, Perugini AG, Veneziano V, Garippa G, Genchi C, Musella V, Cringoli G, 2006. Cystic echinococcosis in water buffaloes: epidemiological survey and molecular evidence of ovine (G1) and buffalo (G3) strains. Vet Parasitol 137, 262-268.

Conraths FJ, Staubach C, Tackmann K, 2003. Statistics and sample design in epidemiological studies of Echinococcus multilocularis in fox populations. Acta Trop 85, 183-189.

Craig PS, McManus DP, Lightowlers MW, Chabalgoity JA, Garcia HH, Gavidia CM, Gilman RH, Gonzalez AE, Lorca M, Naquira C, Nieto A, Schantz PM, 2007. Prevention and control of cystic echinococcosis. Lancet Infect Dis 7, 385-394.

Cringoli G, Rinaldi L, Veneziano V, Musella V, 2005. Disease mapping and risk assessment in veterinary parasitology: some case studies. Parassitologia 47, 9-25.

Danson FM, Giraudoux P, Craig PS, 2006. Spatial modelling and ecology of Echinococcus multilocularis transmission in China. Parasitol Int 55, S227-S231.

Danson FM, Graham AJ, Pleydell DR, Campos-Ponce M, Giraudoux P, Craig PS, 2003. Multi-scale spatial analysis of human alveolar echinococcosis risk in China. Parasitology 127, S133-141.

Daryani A, Alaei R, Arab R, Sharif M, Dehghan MH, Ziaei $H, 2007$. The prevalence, intensity and viability of hydatid cysts in slaughtered animals in the Ardabil province of Northwest Iran. J Helminthol 81, 13-17.

Graham AJ, Danson FM, Giraudoux P, Craig PS, 2004. Ecological epidemiology: landscape metrics and human alveolar echinococossis. Acta Trop 91, 267-278.

McManus DP, Zhang W, Li J, Bartley PB, 2003. Echinococcosis. Lancet 18, 1295-1304.

Moro P, Schantz PM, 2006. Cystic echinococcosis in the Americas. Parasitol Int 55, S181-186.

Nakao M, McManus DP, Schantz PM, Craig PS, Ito A, 2007.

A molecular phylogeny of the genus Echinococcus inferred from complete mitochondrial genomes. Parasitology 134, 713-722.

Rinaldi L, Maurelli MP, Capuano F, Perugini AG, Veneziano V, 
Cringoli G, 2007. Molecular update on cystic echinococosis in cattle and water buffaloes. Zoonoses Public Health, in press.

Rinaldi L, Musella V, Biggeri A, Cringoli G, 2006. New insights into the application of geographical information systems and remote sensing in veterinary parasitology. Geospatial Health 1, 33-47.

Romig T, 2003. Epidemiology of echinococcosis. Langenbecks Arch Surg 388, 209-217.

Scala A, Garippa G, Varcasia A, Tranquillo VM, Genchi C, 2006. Cystic echinococcosis in slaughtered sheep in Sardinia (Italy). Vet Parasitol 15, 33-38.

Scala A, Varcasia A, Garippa G, 2004. Cystic echinococcosis in Sardinia: the current role of sheep. Parassitologia 46,
397-400.

Staubach C, Thulke HH, Tackmann K, Hugh-Jones M, Conraths FJ, 2001. Geographic information system-aided analysis of factors associated with the spatial distribution of Echinococcus multilocularis infections of foxes. Am J Trop Med Hyg 65, 943-948.

Veneziano V, Rinaldi L, Apicella G, Garippa G, Cringoli G, 2004. Cystic echinococcosis in the Campania region (southern Italy). Parassitologia 46, 449-451.

Xiao N, Qiu J, Nakao M, Li T, Yang W, Chen X, Schantz PM, Craig PS, Ito A, 2005. Echinococcus shiquicus n. sp., a taeniid cestode from Tibetan fox and plateau pika in China. Int J Parasitol 35, 693-701. 